\title{
"EYE BALL HANGER"-AN INDIGENOUSLY DESIGNED DEVICE FOR DONOR CORNEAL EVALUATION IN ENUCLEATED EYES.
}

\author{
P. Sudhir Babu, G. Amaresh
}

1. Associate Professor. Department of Ophthalmology, Kamineni Institute of Medical Sciences, Narketpally,

2. Professor \& HOD. Department of Ophthalmology, Kamineni Institute of Medical Sciences, Narketpally,

\section{CORRESPONDING AUTHOR:}

Dr.P Sudhir Babu,

Associate Professor, Department of Ophthalmology,

Kamineni Institute of Medical Sciences,

Narketpally- 508254, Nalagonda dist,

Andhra Pradesh.

E-mail: spadgul@gmail.com

Ph: 00919701896996

INTRODUCTION: Outcome of a corneal transplant surgery mainly depends on the functional reserve of the cornea being transplanted. Thus Donor corneal tissue evaluation forms a vital step in assessing the viability of the graft. Cornea retrieval can be done as an in situ corneal button excision or whole globe enucleation. Studies have shown that enucleation causes less corneal damage and striae as compared to in situ Corneo scleral button excision. ${ }^{1}$ As soon as the eye is received at the eye bank corneal evaluation is done by corneal surgeon using slit lamp and specular microscope, and the cornea is graded, labeled and sent for storage.

Before evaluation, cornea should be allowed to come to room temperature. Whole globe or corneo sclera button should not be left at room temperature for more than one hour.

CORNEAL EVALUATION: Gross Evaluation: Initial evaluation is done by torch light examination, and looked for any gross corneal changes, like corneal folds, oedema, Pannus, Epithelial Defects etc.

Slit Lamp Examination: This is an orderly examination of each layer of the cornea in the centre and periphery both. Initially cornea is examined at low power magnification and illumination is kept at 30 degree angle and followed by high power examination. Cornea is examined for any epithelial defects, epithelial oedema Pannus, defect in the Bowmans membrane, stromal opacities, oedema, ghost vessels, descemets folds and corneal opacities. Endothelium is examined by specular reflection but best studied with Specular Microscope. Look for Keratic Precipitates behind endothelium. Anterior chamber is scanned for presence of any abnormal contents, flare, cells hyopyon, hyphema. Iris is examined for atrophic patches, new vessels and posterior synechiae. Phakic status of the eye is recorded as cataractous, Aphakia or Pseudophakia.2. Look for Signs of any previous ocular surgery. In most of the eye banks slit lamp examination is performed by holding the globe with moist gauge or through the moist chamber jar itself in front of slit lamp.

Corneal Endothelial Examination: Corneal endothelium is the primary layer responsible for maintaining the corneal transparency and tugor hence assessment of this layer forms a crucial step in determining the corneal graft survival. As per guidelines issued by Director General of 
Health Services, New Delhi - Standards of Eye Banking in India - 2009 Determination of Endothelial cell Density via specular microscopy is standard method of corneal tissue evaluation for all Eye Banks. When it is impossible to obtain an endothelial cell count this requirement may be waived on a case-by-case basis by the Managing Director of eye bank. ${ }^{4}$ Endothelial assessment includes measurement of endothelial cell density, cell pattern ,Pleomorphism, Polymegathism, Guttata, vacuolated cells etc. This gives an estimate of the functional reserve of the donor cornea and sets in the high standards of graft acceptance.2,5. Studies have found out that $3 \%$ of corneas graded as excellent on slit lamp examination were rejected after specular microscopic examination.6,7.

Specular Microscopy: Assessment of endothelium can be done by Specular Microscope, Most of the eye banks use Konan Eye Bank Keratoanalyzer where in Corneas are examined through standard corneal storage media vials after Securing the viewing chamber or storage media vial on the holding device of the specular microscope. Plastic corneal viewing chambers with optically clear lids (originally developed by Bourne) allow non-contact viewing of the specular image.eg; EKA-98 Eye Bank Keratoanalyzer system (specular microscopy and image analysis). Recent advanced specular microscopes are capable of producing endothelial images from corneas still contained within the storage media vial, thus further reducing handling of the cornea. ${ }^{8}$. Today's microscopes are also equipped with computerised morphometric analysis systems to analyse the change in cell density, average cell size and uniformity of cell shape pre and post keratoplasty.

\section{EYE BALL HANGER (fig 1):}

Eye ball hanger is a simple instrument designed by us in Department of Ophthalmology at Kamineni Institute Of Medical Sciences, Narketpally, with available resources which enables us to examine and grade the donor corneas of enucleated eyes using regular slit lamp and Specular Microscope (Topcon SP 3000 P).

NEED FOR THE INSTRUMENT: While various methods have been applied for slit lamp evaluation and specular microscopy of the donor cornea, direct examination through the plastic jar or moist chamber will give inadequate visualisation of the cornea in concern. And newer computerised morphometric studies give excellent results but require high end instruments with high cost exchequer to the eye bank.

Regular Topcon Specular Microscope is used for in vivo corneal endothelial assessment and central corneal thickness measurement, where in the patient sits in front of the microscope and keeps his chin on the chin rest with fore head touching the head band, after adjusting the height and distance examiner focuses on to the cornea and image of the corneal endothelium is captured and readings recorded. Same specular microscope can be used for examination of the enucleated eyes , after mounting the enucleated eye on to the eye ball hanger, so that examiner gets to see the direct view of the in situ cornea and grade the cornea before taking a corneo scleral button and sending it for storage.

As This Eye Ball Hanger is a detachable device, it can be mounted on to the head band of the regular Slit Lamp (fig.2) and Specular Microscope (fig.3,4) when ever needed for donor eye evaluation. Rest of the time slit lamp and specular microscope can be utilised for examination of the patients. 
PARTS OF THE INSTRUMENT: Consists of two parts:

\section{1.) Eye ball Holder}

2.) Hanger

Eye ball holder (fig.5,6): This is created by using globe holder from moist chamber jar (fig 5). It consists of three arms and a base. Arms can be expanded and compressed gently to accommodate the enucleated eye ball, these arms also provide stability to the eye ball during in situ examination of the cornea. Base has got a hole to which an indigenously designed hanger is attached and tightened with the screw.

Hanger: This is an indigenously designed part using the side arm of condemned trial frame (fig.7, 8), which is bent and shaped to be hanged on to head band or head rest of the slit lamp and specular microscope.

\section{MATERIALS USED:}

1.) Globe Holder of moist chamber jar (fig 5,6 )

2.) Side Arm of Condemned Trial Frame. (fig 7, 8)

\section{ADVANTAGES:}

1.) Cheap and cost effective

2.) Can utilize same specular microscope for both enucleated eye examination and routine corneal evaluation of patients.

3.) Made of easily available materials.

4.) Can be utilised for Research purpose.

\section{DISADVANTAGES:}

1.) Careful Tissue handling required while mounting the globe on to the hanger.

2.) Cornea becomes dry if kept for long time in the room air during corneal evaluation thus requiring frequent application of antibiotic drops to keep the cornea moist and better endothelial visualisation.

ACKNOWLEDGEMENT: We sincerely thank our Chairman, Secretary Kamineni Education Society, Principal, KIMS and Medical Superintendent of KIMS Hospital for giving us opportunity and their continuous support and encouragement.

\section{REFERENCES:}

1. Lane S.S. et al, Whole globe enucleation versus in situ corneal excision, Cornea 13:305309,1994.

2. Dr Graeme Pollock- eye banking - a practical Guide

3. Laing RA. Specular microscopy of donor corneas. In Brightbill FS, editor: Corneal surgery: theory, technique and tissue, Edition 2. St Louis, Mosby-Year Book, 1993. p. 575-586.

4. National programme for control of blindness ;Standards of eye banking India ; 2009

5. Pels Elisabeth, Beele Hilde, and Claerhout Ilse Eye bank issues: II. Preservation techniques: warm versus cold storage Int Ophthalmol. 2008 June; 28(3): 155-163. 
6. Jagjit S Saini, Madhukar K Reddy, AK Jain, MS Ravindra, Sameera Jhaveria, Lalitha Raghuram; Perspectives in eye banking;Ophthalmology Practice;1996;44(1);47-55.

7. Jagjit S Saini ,Madhukar Reddy , Savitri Sharma ,Sangeeta Wagh;Donor corneal tissue evaluation;current ophthalmology;1996;44(1);3-13

8. Bourne WM. Examination and photography of donor corneal endothelium. Arch Ophthalmol 94: 1799-1800, 1976.

9. Mattern RM, Heck EL, Cavanagh HD. The impact on tissue utilization of screening donor corneas by specular microscopy at the University of Texas South western medical Center. Cornea 14: 562-7, 1995.
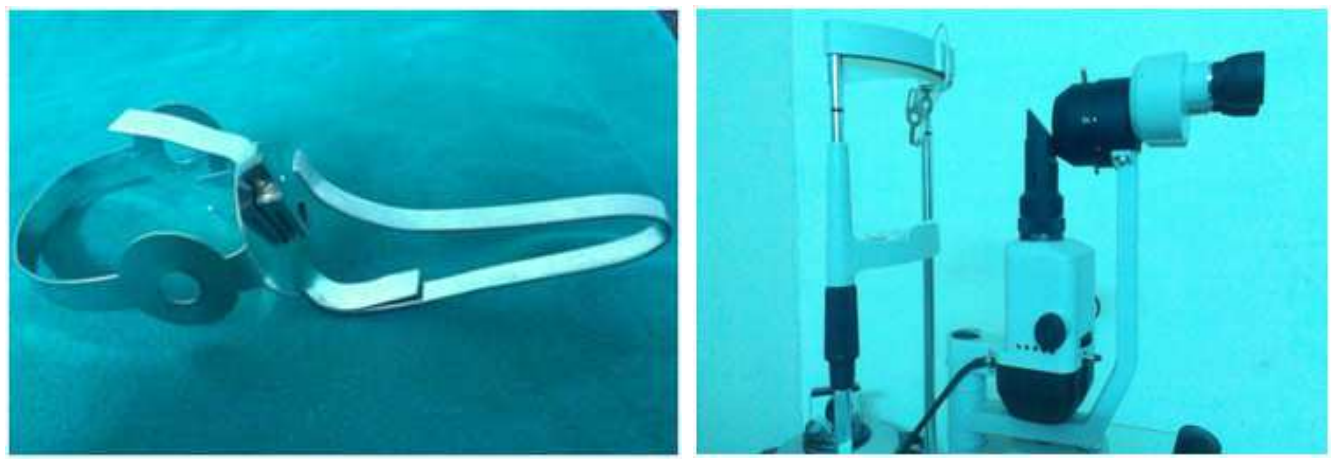

Figure 1. Eye Ball Hanger

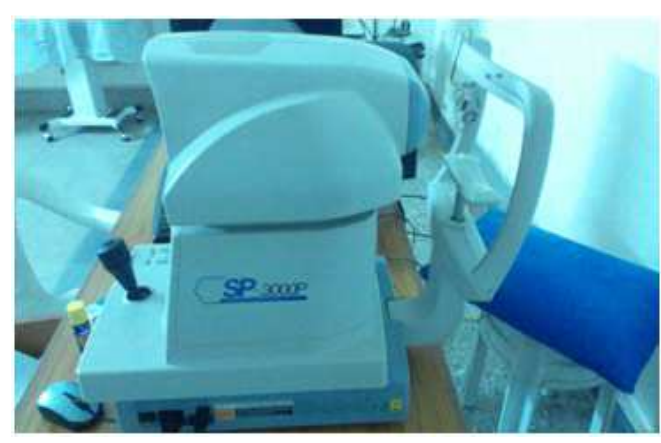

Figure 3. Eye Ball Hanger Mounted on to Specular Microscope.

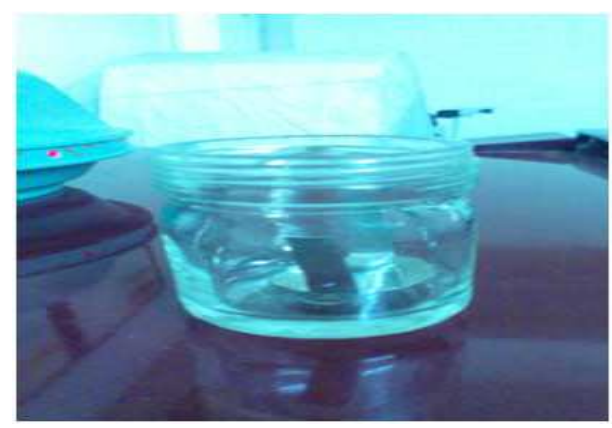

Figure 5. Globe Holder in Moist Chamber
Figure 2. Eye Ball Hanger Mounted on to Slit Lamp.

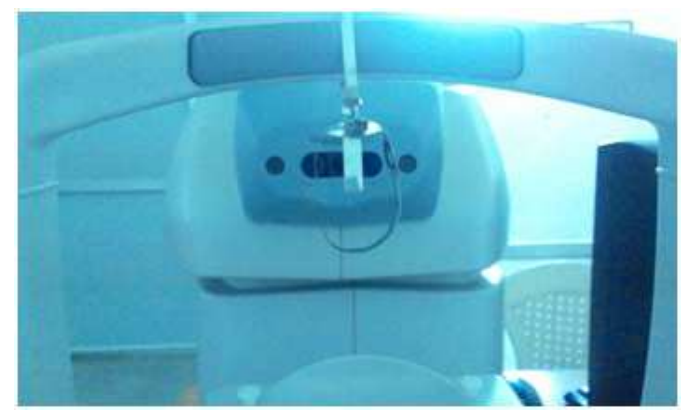

Figure 4. Eye Ball Holder Mounted on to Specular Microscope.

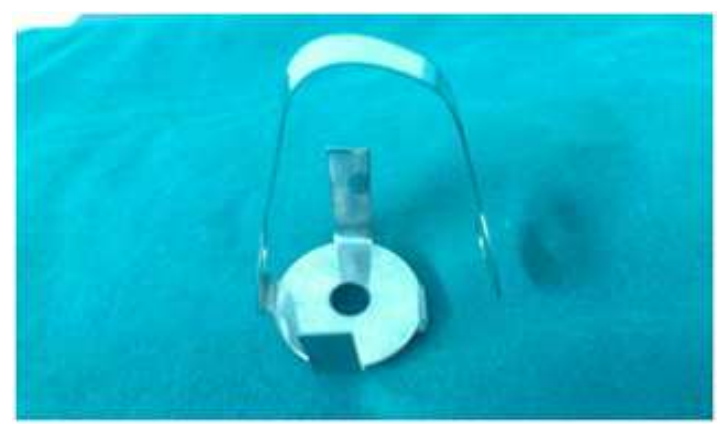

Figure 6. Globe Holder with three arms and a base with hole 


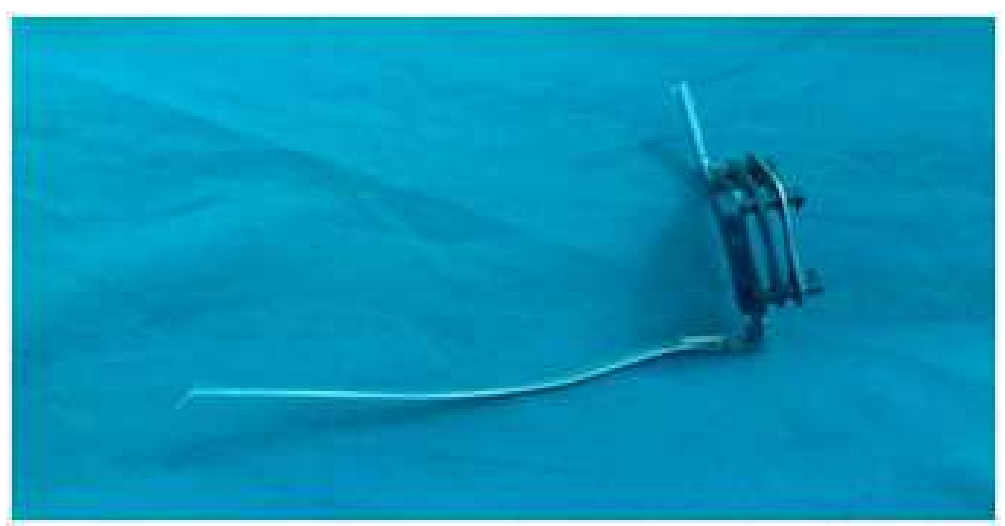

Figure 7. Condemned Trial Frame

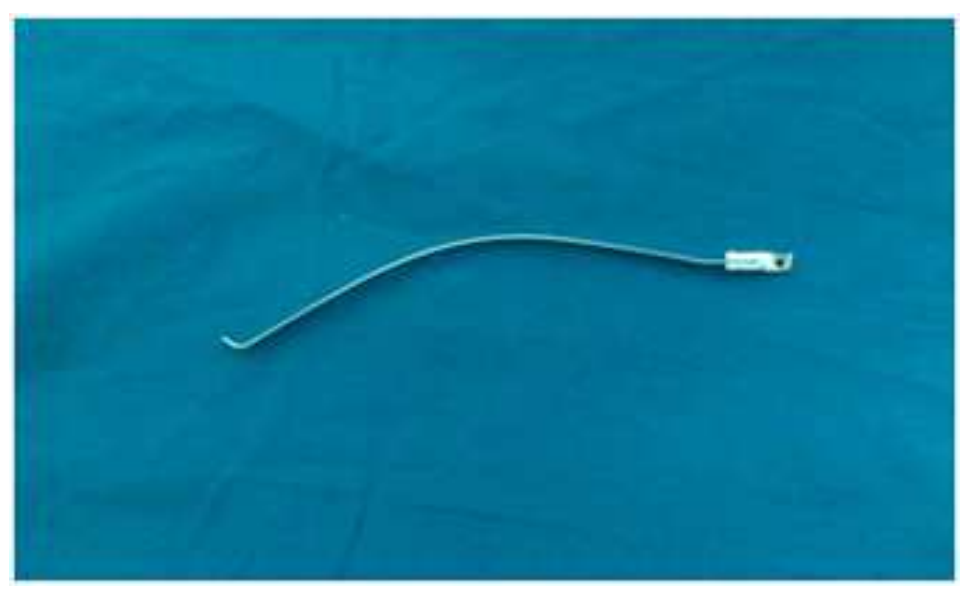

Figure 8. Arm of condemned Trial Frame.

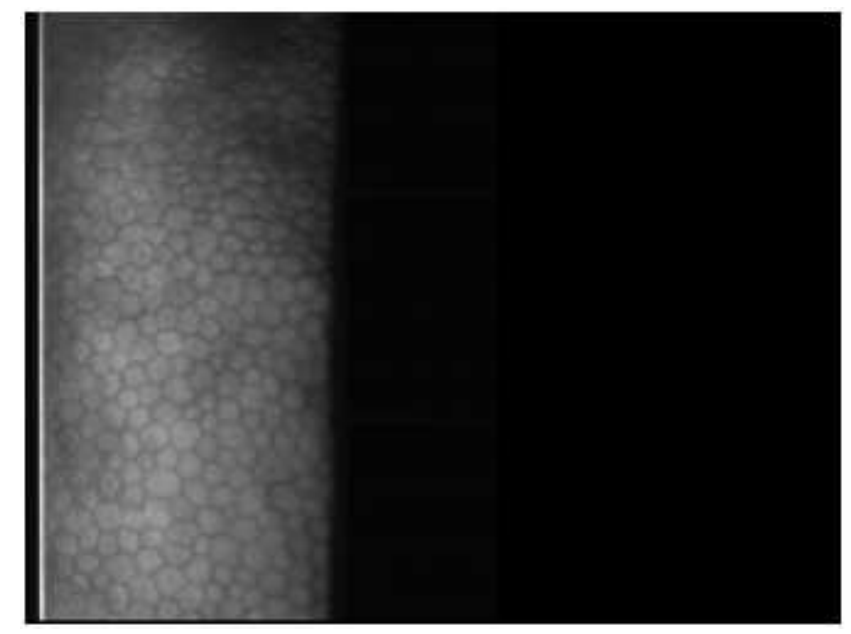

Figure 9. Corneal Endothelial Image taken from Specular Microscope on an Enucleated eye. 